\title{
A Study on the Structure of Heroic Narratives in the Tale of Taoist Wizard <Jeonwuchi>
}

\author{
Jung-Gon Lee1), Duk-Hwan Kim²), Dae-Yul Jeong3)
}

\begin{abstract}
This paper examines the structural aspects of heroic narratives in the classic novel <Jeonwuchijeon: Tale of Jeonwuchi $>$ and the modern movie $<$ Jeonwuchi $>$. The novel is a work depicting the heroic achievements of Taoist wizard Jeonwuchi, the main character in the novel. It also analyzes the discourse structure of the film version of the tale, <Jeonwuchi>, through Joseph Campbell's theory of the Hero's Journey. The main objectives of this paper are to identify the limits of modern modifications of cultural archetypes based on Jeonwuchi's heroism, and to seek out new directions for the reproduction of glocal (global + local) cultural contents. Unlike the original text, the film's discourse structure related to heroism is either diminished entirely or modified into various narratives. The protagonist Jeonwuchi and his story especially has been re-imagined in a way that depicts him as a rather playful character. This kind of characterization is problematic for the reproduction of future cultural contents involving heroes because the literary narratives and works featuring Jeonwuchi that have been passed down and modified all contain elements of a hero narrative. By channeling his superhuman abilities (Taoist magic), Jeonwuchi helps the people and gains power for himself as well. This kind of narrative element makes one see the potential of storytelling that features Korea's unique heroism which may even allow it to become cultural contents on a global scale. Therefore, this paper rediscover the value of Korean hero narratives through a literary review of the archetype and analysis of narrative structure of the film <Jeonwuchi> based on Joseph Campbell's theory of the Hero's Journey and Christopher Vogler's writing methodology. Based on the results, this paper concludes that Campbell's theory is indeed an effective method which upon the narratives of the $<$ Tale of Jeonwuchi> can be established as a new genre in the form of 'Korean hero contents'.
\end{abstract}

Keywords: Heroic Narratives, Jeonwuchijeon, Movie Jeonwuchi, Classic Novel, Glocal Cultural Contents

\section{Introduction}

This paper examines the structure of the elements of a hero in the film <Jeonwuchi $>$ based on

Received(May 03, 2020), Review Result(1st: June 19, 2020, 2nd: August 11, 2020), Accepted(September 25, 2020)

1) (Candidate Ph. D.) 52828 Dept. of Cultural Convergence, Gyeongsang National University, Jinju, Gyeongsangnam-do, Korea

email: baekunsan@hanmail.net

2) (Professor) 52828 Dept. of Chinese Language and Literature, Gyeongsang National University, Jinju, Gyeongsangnam-do, Korea

email: mugam20@hanmail.net

3) (Professor, Corresponding Author) 52828 Dept. of Management Information Systems, Gyeongsang National University, Jinju, Gyeongsangnam-do, Korea

email: dyjeong@gnu.ac.kr 
Campbell's theory of the Hero's Journey, which describes hero myth patterns in terms of the mono-myth, and this is done in order to consider the methodological aspects of developing glocal cultural contents. The paper, however, will focus primarily on examining the aspects of the elements of heroic narratives found within the literature narratives and tales that have been passed down to the early 20th century featuring the archetypal hero, Jeonwuchi.

Before one attempts to recreate classics into modern media artwork, it is essential that one conducts a bibliographical study of the fables, folktales, and legends that form the roots of Korean culture from multiple angles. This is because archetypes like Jeonwuchi, in other words, archetypes that can be defined as various patterns of ancient characters that people share today, are not set in stone. Rather than using fixed characters that artists and writers depict whilst adhering to the archetype, one should carry out characterization that leaves room for the character to function in a flexible way, and this in turn will improve one's ability to reproduce storytelling in a more systematic and creative manner. In addition, Vogler states that it is not only the mythological imagination but also the possibility of an archetype (much like the mono-myth) and the understanding of that power that are ever-present within the dreams and character of an individual. And that are the most powerful tools a storyteller keeps inside his or her magic bag[1].

<Jeonwuchi-jeon: Tale of Jeonwuchi> is a literary work that features a real person who existed during the Joseon Dynasty period, and it is a classical novel that follows the story of Jeonwuchi, a man who has superhuman powers[2-5]. The novel's central plot can be summed up as follows: the story begins with the protagonist Jeonwuchi earning his superhuman abilities (Taoist magic) with the help of supernatural beings such as a Taoist hermit, ascetic, or Kumiho, the legendary nine-tailed fox. After witnessing the people suffering from poverty and destitution, Jeonwuchi is determined to use his powers to save them from their plight. Disguising himself as a messenger from heaven, he then flies to the royal court and asks the king to donate a golden beam, which he then subsequently sells in order to help the people. He continues performing good deeds by helping the wrongly accused, curing the sick, arresting bandits, and punishing corrupt officials whilst serving in a government position himself. The story concludes with Jeonwuchi either becoming the king of the Yan Dynasty of China or following his mentor Hwadam into the mountains to find enlightenment.

The original text of <Jeonwuchi-jeon> can be categorized into four different versions (bon) according to the date of publication: 'Hanmunbon, Ilsabon, Nasonbon, Sinmungwanbon'[6]. It is worth noting that $\mathrm{Ahn}(2011)$ points out Jeonwuchi is an egocentric individual, and when he becomes a government official and arrests Uhmjun, he becomes a representative of the ruling 
order, thus collapsing his identity as a people's hero[7]. On the contrary, however, Jeonwuchi can definitely be seen as a people's hero because he uses magic to help the people, oppose corrupt government officials of the late Joseon Dynasty, render social justice and solve social problems. Therefore, this paper will analyze the 'contents of the hero's story' in the $<$ Jeonwuchi-jeon> through the three versions of the story excluding the Hanmunbon version, which includes a significant amount of negative accounts of the story.

In Campbell's mono-myth, the hero ultimately becomes the victor after going through a journey. The word 'hero' originates from the Greek word for 'protect and serve.' The ones who need to be protected and served are the ones who face difficulty by being treated unjustly. Thus, this paper will focus primarily on how the protagonist Jeonwuchi, undergoing multiple changes through various versions of the classical novel, came to have the elements of the 'hero story' in which the hero protects and serves the people.

This paper hypothesizes that one can create an authentic character in a 'Korean hero movie' and pave the way for a new understanding only after drawing elements of a hero based on the three different versions, Ilsa-bon(Gyeonpan 37th), Nason-bon (written by Dongwuk Kim), and Sinmungwan-bon(written by Namsun Choi). Secondly, only after a thorough review of the literature and film can one identify the problems rising from the modification or diminishing of heroism carried out by the director of the modern digital media film <Jeonwuchi> and subsequently come up with alternatives for the recreation of new cultural content. In order to accomplish this and ultimately consider the possibilities of the' Korean hero movie,' this paper will conduct a literature analysis and examine character of Jeonwuchi, which has been reimagined in a multidimensional way in the film <Jeonwuchi>, and the discourse structure of character based on Joseph Campbell's '17 Stages of the Heroe's Journey' and Christopher Vogler's own abridged version of the 12 stages[1][8].

\section{Variations and Features of Heroic Narratives in <Jeonwuchi-jeon>}

$<$ Jeonwuchi-jeon> is a tale that was inspired by the life of a real person who lived during the 16th century. The tale was passed on down as a classical novel with 13 different versions which had popular appeal among a wide range of readers until the early to mid 20th century[6]. On the other hand, the Hanmunbon version and parts of the folktale contain accounts of Jeonwuchi committing illegal and wicked deeds for his personal interests and amusement. That is the reason why Jeonwuchi's story was evaluated clearly as either that of a hero or non-hero, of success or failure. 
However, the vast majority of the Ilsa-bon (Gyeonpan 37 Jang-bon), Nason-bon, Sinmungwan-bon versions' narratives depict Jeonwuchi as an ascetic who reaches an extraordinary level and uses his abilities to help those in need and fights for social justice. This kind of material is suitable enough to be used in a 'heroic narrative'. And the concept of a hero who masters the ways of Taoist magic and uses supernatural powers is one that could be gladly welcomed by today's cultural content industry. This kind of narrative is also in line with Campbell and Vogler's take on the heroic narrative.

$<$ Jeonwuchi-jeon> is a popular Korean cultural contents that is in the same vein as tales such as the <Tale of Hong Gildong>, <Tale of Chunhyang>, and the <Tale of Simcheong>. Additionally, Jeonwuchi is known widely across the country as both a real person and a character in a heroic tale, appearing in tales from regions such as Haeseo, Songgyeong, Seoul, Damyang, and Gwangyang[9].

This means that the tale is not limited to one area but boasts ample expandability as a form of contents. Until now the heroic narrative of Korean folktales was divided mainly into aristocratic hero stories and popular hero stories. Jeonwuchi's story belongs to the latter and takes on the plot of 'lowly status - acquires magical abilities - crisis - struggle - overcomes the crisis - becomes the victor'[10]. It is important to avoid confining the heroic narrative of Jeonwuchi's tales within the research for 'positive and negative' world views, and one needs to prepare and propose ways that can sublimate the tales into modern works of art. Not only that, views that claim Jeonwuchi cannot be a 'popular hero' are losing significance in various researches on modern modification.

Therefore, this paper draws and arranges the 'aspects of the heroic narrative' found within the Nason-bon, Ilsa-bon, Sinmungwan-bon versions in [Table 1] and reconfirms Jeonwuchi's character as a popular hero. <Jeonwuchijeon> covered in [Table 1] contains mostly positive aspects of the heroic story. Based on the preceding researches, [Table 1] features the aspects and characteristics of the heroic narrative summarized, divided, and rearranged into three major categories[2][3][6][9][11-15].

The original tale is set mainly in China and the Joseon Dynasty, and the attitude of the tales toward Jeonwuchi, including that of folktales and novels, goes from positive (16th century) - negative (17th century) - orderly(18th century onwards)[11][14]. Wuchi's portrayal as both a positive and negative character is due to the political causes of the time. During the 17th century, the people of power in the Joseon Dynasty dealt with those who dared to challenge their authority by accusing them of high treason. In other words, Jeonwuchi, who dared to toy with the king, exposed the malaise of the caste system, and punished corrupt 
administrative offices and officials, was seen as a treasonous traitor. The ones in power sought to disparage Jeonwuchi, and this probably led to the rise of the Hanmun-bon version with the negative portrayal of the character in the 17th century. In the Hanmun-bon, Jeonwuchi's heroic aspects are mostly depicted in negative ways, and the parts about him being a popular hero are also removed.

[Table 1] Aspects of the Heroic Narratives (Elements) of Jeonwuchi

\begin{tabular}{|c|c|c|}
\hline Ilsa- & Nason-bon(Kimdongw & Sinmungwan-bon[3] \\
\hline $\begin{array}{l}\text { (1) As a banishment from } \\
\text { heaven motif, Jeonwuchi, } \\
\text { originally a member of the } \\
\text { heavens, is reincarnated on } \\
\text { earth. } \\
\text { (2) Wuchi meets his mentor } \\
\text { Yoon Gong, acquires the } \\
\text { magical marble and the } \\
\text { Heavenly Book from the fox } \\
\text { and Kumiho, and learns Taoist } \\
\text { magic. } \\
\text { (3) Demands a golden beam } \\
\text { from the king and sells it to } \\
\text { help the people. } \\
\text { (4) Helps a person who was } \\
\text { wrongly accused of murder and } \\
\text { sentenced to death. } \\
\text { (5) Confronts a corrupt official } \\
\text { who steals from people and } \\
\text { teaches him a lesson. } \\
\text { (6) Disciplines an arrogant } \\
\text { scholar. } \\
\text { (7) Saves a person who faces } \\
\text { death due to false charges. } \\
\text { (8) Enters the royal court and } \\
\text { receives a government position } \\
\text { (9) Subjugates Uhmjun the } \\
\text { bandit and pardons him, } \\
\text { allowing him to live as a } \\
\text { civilian (Uhmjun was considered } \\
\text { to be and researched as a } \\
\text { righteous outlaw like Hong } \\
\text { Gyeongnae). } \\
\text { (10) Teaches Wang Yeonhee, who } \\
\text { tried to kill Wuchi out of } \\
\text { jealousy, a lesson } \\
\text { (11) Transforms Lady Min, }\end{array}$ & $\begin{array}{l}\text { (1) Gangwon Province, in the } \\
\text { early days of King Injo's reign, } \\
\text { Jeon Jungbo(Wuchi's father) } \\
\text { offers sacks of rice to the } \\
\text { people. } \\
\text { (2) His wife Lady Choi has a } \\
\text { conception dream and gives } \\
\text { birth to Jeon Wuchi after being } \\
\text { pregnant for } 15 \text { months. } \\
\text { (3) Jeon Wuchi's father sends } \\
\text { him to a mountain temple for } \\
\text { education } \\
\text { (4) Wuchi learns special abilities } \\
\text { from his old mentor. } \\
\text { (5) Wuchi's father attempts to } \\
\text { kill his son after learning from } \\
\text { a fortune-teller that Wuchi has } \\
\text { the makings of becoming an } \\
\text { emperor } \\
\text { (6) Wuchi leaves his home and } \\
\text { becomes a bandit leader } \\
\text { (7) He steals from Yeongcheon } \\
\text { Temple } \\
\text { (8) He deceives the emperor and } \\
\text { acquires a golden beam. } \\
\text { (9) He gives the bandits gold } \\
\text { and silver, saves their lives and } \\
\text { lets them live } \\
\text { (10) The emperor sends an } \\
\text { emissary to Joseon and has } \\
\text { Jeonwuchi arrested. } \\
\text { (11) The emperor sends an } \\
\text { emissary to Joseon and has Jeon } \\
\text { Wuchi arrested } \\
\text { (12) Becomes close with the } \\
\text { princess of the Yan Dynasty in } \\
\text { China and becomes the king's }\end{array}$ & $\begin{array}{l}\text { (1) Learns magical abilities from } \\
\text { his mentor. } \\
\text { (2) Jeonwuchi resolves to use his } \\
\text { abilities to help the people of } \\
\text { the kingdom after witnessing } \\
\text { the government not taking care } \\
\text { of its people even during times } \\
\text { of famine and bandit attacks. } \\
\text { (3) Acquires a golden beam } \\
\text { from the king and sells it to } \\
\text { help the people } \\
\text { (4) Helps a person who was } \\
\text { wrongly accused of murder and } \\
\text { sentenced to death } \\
\text { (5) Confronts a corrupt official } \\
\text { who steals from people and } \\
\text { teaches him a lesson. } \\
\text { (6) Disciplines an arrogant } \\
\text { scholar } \\
\text { (7) Saves the noble Jang Sechang } \\
\text { from dying wrongfully from } \\
\text { false charges. } \\
\text { (8) Enters the royal court and } \\
\text { receives a government position. } \\
\text { (9) Subjugates Uhmjun the } \\
\text { bandit and pardons him, } \\
\text { allowing him to live as a } \\
\text { civilian. } \\
\text { (10) Is falsely accused as a } \\
\text { traitor, draws a picture of a } \\
\text { donkey and escapes on the } \\
\text { donkey (Similar to the film's } \\
\text { scene of Stage } 1 \text { ). } \\
\text { (11) Teaches Wang Yeonhee, who } \\
\text { tried to kill Wuchi out of } \\
\text { jealousy and corrupt officials, a } \\
\text { lesson }\end{array}$ \\
\hline
\end{tabular}




\begin{tabular}{|l|l|l|}
\hline $\begin{array}{l}\text { Oh-Saeng's jealous wife, into a } \\
\text { snake and makes her repent. }\end{array}$ & $\begin{array}{l}\text { son-in-law } \\
\text { (13) Inherits the throne and } \\
\text { (12) Has a martial arts duel with } \\
\text { becomes the king of Yan }\end{array}$ & $\begin{array}{l}\text { Taebaek Mountain } \\
\text { wongdam, and Seo Hwadam } \\
\text { Dyanasty. }\end{array}$ \\
attempts to trap and kill & & \\
Kumiho with a stone chest & & \\
(13) Heads into Yeongju & & \\
Mountain with Seo Hwadam to \\
achieve enlightenment.
\end{tabular}

As is the case, [Table 1] uses the categorization by preceding researches in order to determine the existence of a heroic character and draw out the 'aspects of a hero narrative' in the different versions of the tale. According Sang-Gu Lee(2009) and Hyeeun Seo(2018), the chronological order of the different versions' publication is estimated as follows: 'Hanmun-bon $\rightarrow$ Ilsa-bon $\rightarrow$ Nason-bon $\rightarrow$ Sinmungwan-bon.' There are some inexact dates and overlaps, but the ordering is valuable in attempts to understand the changes in hero narrative and its aspects sequentially[6][14].

In addition, the Sinmungwan-bon version, which is considered to be version of the Ilsa-bon texts[16], depicts Jeonwuchi acquiring his Taoist magic through supernatural circumstances, a feature characteristic of the Ilsa-bon version and Nason-bon version. Jeonwuchi, an initially ordinary man, acquires the Heavenly Book from the fox, Kumiho and receives tutelage from a masterful mentor, eventually learning Taoist magic. It is also stated that Wuchi was originally quite talented and showed great devotion, traits that thus allowed him to understand the mysteries of the world and acquire superhuman abilities.

This is very similar to the part in Campbell's version of the hero's story in which the hero acquires an extraordinary skill, ability or magic. Acquiring magical abilities through the fox's magical marble and Heavenly Book or through a mentor's tutelage is an important element, as seen in the 'Meeting the Mentor' stage set out by Campbell and Vogler's stages of the Hero's Journey. In his '17 Stages of the Hero's Journey' Campbell analyzes the aspects of heroic narratives within ancient mythology, religion, folk culture, local folklore and legends from the East and the West and theorizes his findings in terms of the mono-myth. Because the protagonist Jeonwuchi seeks to help the people, reform society and adhere to ethnic autonomy, he has the makings of a popular hero, thus, can be categorized comprehensively through Campbell's theory.

Much of the heroes featured in Korean myths and classic novels travel while riding clouds, use superhuman abilities such as magic and metamorphosis, receive assistance from supernatural 
beings or mentors, and stand against enemies. Ths kind of narrative is not only found in the film version of Jeonwuchi's tale, <Jeonwuchi> but also in many scenes in <The Lord of the Rings $>$. This is why the tales of Jeonwuchi are a very significant subject that can be recreated today as a very interesting form of cultural contents.

\section{Campbell's Theory for Heroic Contents Development}

Campbell[8] claims there are universal components or patterns in hero stories from ancient myths and calls them the 'Hero's Journey' or the 'Hero's Adventure.' He then used this pattern to examine the events and tangible and intangible changes related to heroes within myths, legends, folktales, and religion. Meanwhile, Vogler[1], based on his studies of modern and contemporary films, examined scenarios and plots featuring heroism and explained the direction of writing in terms of the Hero's Journey.

Recent years, it has seen vigorous development and research of global cultural content using Korea's classic cultural archetypes. There are, however, debates regarding the methods of transforming cultural archetypes and the timeliness of said methods. This is mainly because of recent trends that saw drastic changes forms of expression in art and culture due to the shift from the tangible to the intangible, from analogue to digital technology, and from hardware to software. Therefore, it is clear that the various debates on the methodology of to producing world-class contents based on Korean classic novels are already more than commonplace. [4][5][7][13][17] Contemporary world-class art as a cultural contents can become a high value products because such contents can have a great ripple effect even on social and industrial areas.

The heroism in <Jeonwuchi-jeon> has been adopted and recreated into new forms of modern art forms such as a movie (2009), TV series (2012), and animation (2015; 'Hello, Jeonwuchi! The Robot Armageddon'). Such processes are not merely one of genre conversion but could become ways to give birth to a new genre, a 'Korean hero contents.' Applying Campbell's theory of the 'Hero's Journey' from his mono-myth is perhaps one way to discuss further regarding such processes. Futhermore, Hollywood-style scenario writing method to develop cultural contents may be valuable in developing Korea's heroic characters. The contents could be loved and enjoyed by people around the world.

In Korea, for example, the film <Along with the Gods> made in 2017 adopted the Korean traditional myths <Chasabonpulyi> and <Jeoseungbonpulyi>, and it featured gods and grim reapers from Korean mythology and told a satirical tale about the fates of gods and humans. 
The myth is a kind of shaman performance for a dead person which descends from Jeju Island in Korea. One reason for the film's success can be found in the fact that it was based on an online comic series that adapted the cultural archetype as its source material. In addition, the film featured touching discourses and included stories that dealt with subjects such as life and death, the current life and the life after death, and sin and punishment. Such aspects are also similarly featured in Campbell's mono-myth. It can also be said that the protagonist Gang-lim (the grim reaper) was depicted as not only having humane traits (compassion, love) but also heroic aspects, thus it can be said that it has also created a unique hero who is likable and relatable.

There are many blockbuster movies that were based on Campbell's theory, such as <Star Wars $>$, <Harry Potter $>$, <Lord of the Rings $>$, <The Chronicles of Narnia $>$, <Superman>, <Iron Man>, and <The Matrix>. All these films are global cultural contents that have plots based on the heroic narrative, and as well got great commercial success.

Campbell claims that in the first act of 'Departure', the heroic protagonist goes through difficulties in the midst of everyday life, encounters a herald who informs him of the impending crises, and acquires superhuman abilities through the aid of a mentor or an assistant. In the second act 'Initiation', the hero overcomes various challenges, experiences self-awakening and growth through overcoming confrontational situations such as wars and fights, and ultimately becomes a hero that will be beneficial to the world through apotheosis. In the third act 'Return', the hero overcomes many more challenges, is resurrected, achieves a life of freedom, and returns to everyday life (or his home or past)[1][8].

[Table 2] Comparison of Hero's Journey between Joseph Campbell and Christopher Vogler

\begin{tabular}{|ll|ll|}
\hline \multicolumn{2}{|c|}{ Joseph Campbell[8] } & \multicolumn{2}{c|}{ Christopher Vogler[1] } \\
\hline Stages & Departure & Stages & Act 1 \\
\hline 1 & The call to adventure & 1 & Ordinary world \\
2 & Refusal of the call & 2 & $\begin{array}{l}\text { Call to adventure } \\
\text { Refusal of the cal }\end{array}$ \\
3 & Supernatural aid & 3 & Meeting with the mentor \\
4 & Crossing the threshold & 4 & Crossing the first threshold \\
5 & Belly of Whale & 5 & Act 2 \\
\hline & Initiation & & Tests, allies and enemies \\
\hline 6 & The Road of Trials & 6 & Approach to the inmost cave \\
7 & The Meeting with the Goddess & 7 & The ordeal \\
8 & Woman as temptress & 8 & \\
9 & Atonement with the father & &
\end{tabular}




\begin{tabular}{|ll|ll|}
10 & $\begin{array}{l}\text { Apotheosis } \\
\text { The ultimate boon }\end{array}$ & 9 & The Reward \\
\hline & Return & 10 & Act 3 \\
\hline 12 & $\begin{array}{l}\text { Refusal of the return } \\
\text { The magic flight }\end{array}$ & \\
13 & $\begin{array}{l}\text { Rescue from without } \\
14\end{array}$ & 11 & The resurrection back \\
15 & The crossing of the return threshold & Master of two worlds & Return with the elixir \\
17 & Freedom to live & 12 & \\
\hline
\end{tabular}

As it is evident in [Table 2], a hero story features a repeatedly dramatic plot comprised of events that include crises, adventures, and wars, and it also always includes supernatural or surreal situations as well as antagonistic objects or antagonists. Campbell especially compared the polarity between beings and nonbeings, the heavens and this world, and good and evil. The bipolar comparison is like a symplegades in Greek mythology that heroic adventurers had to endure. He also stated that a hero always go through this path, becoming aware of his own greatness and finding great success like godly beings[1][8].

The plot of the hero's journey according to Campbell can be summed up as follows: The birth or banishment from heaven of a character (Descends onto the world as the son of heaven, god, or celestial being) $\rightarrow$ Encounters a mentor and acquires supernatural powers $\rightarrow$ Hardship (Trials) $\rightarrow$ Struggle $\rightarrow$ Growth $\rightarrow$ Overcoming $\rightarrow$ Victory (Humanitarian world) $\rightarrow$ Return (Return home, repatriation). The protagonist becomes a hero by going through these stages and accomplishes a great task after an adventure.

This paper compared the stages of Campbell and Vogler in [Table 2] in order to create a new hero character and hero content because Campbell's theory and Vogler's scenario writing methodology that derived from that theory must not be considered as separate subjects but should be recognized in mutually complementary relationship for higher utility. That is why the two theories are suitable for the analysis and reproduction of new hero content. Next section, this paper will apply the Campbell's theory and Vogler's scenario writing methodology to analyze the film <Jeonwuchi> for further development of new contents.

\section{Application of Campbell's Theory to Analyze the Film <Jeonwuchi>}

\subsection{The Aspects of Heroic Narratives in the Film <Jeonwuchi>}

It is extremely encouraging for the development of glocal cultural contents to have various 
precedent researches on the film <Jeonwuchi>. Lee(2010) compared in detail the narrative structures of the film and the novel <Jeonwuchi-jeon>[18]. Sin(2010) and Hyeon(2013) examined the aesthetic characteristics of Korean super-hero film, and offered ways how video contents based on Korean classic novels can find success[19][20]. There are also the various approaches to the transformation, modification and acceptance of modern media[21-23]. Also, many papers suggested the possibilities of glocal contents development of Korean fantasy films[24-27].

Seo(2008) in particular interpreted the archetype <Jeonwuchi-jeon> not as a work of art with a complete structure but as a way of enjoying culture. With that approach, she compared the tale to the film <Bruce Almighty>, viewing both works as having an open structure that allows the addition and modification of new story elements as a way of actively connecting the classic and the modern. By doing this, she tried to conduct a meaningful search for cultural expansion in the modern day[25]. The classic and the modern are like an organism that are connected to one another. The reproduction of cultural contents is possible through imitation, but it is essential that one understands the power (influence) of the archetype and its value as a work of art and use as much imaginative power as possible to discover a new modern sense of value.

The film <Jeonwuchi> directed by Choi Donghoon was released in 2009. Under the title of 'Jeonwuchi: a Korean Hero Movie' the film attracted approximately six million viewers and was deemed a financial success. However, the film did not make the most out of the heroic narrative of the original text. The first reason is that the film completely omitted the various aspects of Jeonwuchi's story such as helping the people in their plight, saving the lives of innocents, subjugating bandits, and punishing corrupt government officials while serving in a government position himself. Secondly, the film was unable to depict Jeonwuchi as a relatable character by failing to feature his aspects as a popular hero.

The fact that the film included only two heroic elements described in [Table 1], namely that of Wuchi aiding the people suffering from the famine and escaping on the donkey that he drew, makes one wonder about the identity of the film's protagonist even before engaging in a discourse of the film. Simply put, elements such as the ability to fly, control the elements and use magic charms does not complete heroism. The fact that the film included only two heroic elements decribed in [Table 1], namely that of Wuchi aiding the people suffering from the famine and escaping on the donkey that he drew, makes one wonder about the identity of the film's protagonist even before engaging in a discourse of the film. Simply put, elements such as the ability to fly, control the elements and use magic charms does not complete heroism.

The film adopts elements from folklore such as that of the Memorabilia of the Three 
Kingdoms and creates a dreamlike plot that jumps back and forth between the primordial heaven (The space time in which Seo Hwadam, the goblins, and the magical flute originate), the Joseon Dynasty era, and the modern day mixed in with elements of martial arts, romance and fantasy. In addition, the film focuses primarily on the playful character of Jeonwuchi, further diminishing his heroism.

Therefore, in order to transform the popular hero Jeonwuchi into a hero character with various and unique personalities as depicted in Hollywood movies, it is necessary to apply Campbell's Hero's Journey or Vogler's writing methodology and analyze them accordingly. Films are, in all respects, a form of composite art consisting of images and a narrative.

\subsection{Applying to Campbell and Vogler's Theories}

Yeojeong Jo(2010) used Campbell's model of the 'Hero's Journey for the myth analysis of <Jeon Wuchi : The Taoist Wizard>[28]. However, the 12 stages that she used are a bit different from that of Vogler. For example, she described the fourth stage not as meeting with the mentor but as meeting with the adviser in terms of Campbell's supernatural assistants, the three wizards. As mentioned before, Vogler's theory adapted Campbell's mono-myth's sequences and principles to create a composition method for modern Hollywood hero movies, and therefore there is not much point in trying to compare the differences between the two theories. This paper adopted Vogler's 12 stages in their entirety in order to analyze the narrative structure of <Jeonwuchi : As the Taoist Wizard>. In addition, the paper examined the parts that are related to Campbell's 'Hero's Journey' theory and drew a conclusion as follows.

Donghoon Choi, the director of the film <Jeonwuchi> said he "wanted to create a fairy tail-like fantasty" and that the film features elements from "Memorabilia of the Three Kingdoms, The Tale of Jeonwuchi, Journey to the West, Macbeth, and Don Quixote." As this suggests, the film has a narrative that is mostly different and a heroism that is completely different from the original text <The Tale of Jeonwuchi>. The director stated that even though his film does not have the same scale as Avatar, the most important thing in the film is the imagination, and he also argues that if Korea's film industry aspires to become more like Hollywood, it has no other option than to develop its imagination. Much like these words, the film depicts Jeonwuchi in a way that is reminiscent of SunWukong and Don Quixote[29].

Jeonwuchi has three places that he can call home. The first is the heavens in which he and his mentor train together, and it is depicted as existing within the oriental painting at a Wudobang shrine. Wuchi lives in this world together with his mentor and Choraengi who can 
transform into a dog, a horse, or a human being. The second place is the Joseon Dynasty, set during a chaotic time after a magic flute has fallen into the hands of goblins and the antagonist HwaDam due to the mistake of three Taoist wizards. The third place is the modern world in which the three wizards, as a way to retrieve the stolen flute, revive Jeonwuchi and Choraengi who have been sealed within a painting for 500 years. It is the modern world that serves as the main setting for the film.

Jeonwuchi has three missions (tasks) to fulfill. The first is to keep the promise of protecting Seo In-kyung, a reincarnation of a women he meets during the Joseon Dynasty era (played by Soo-jung Im in the film). The second is to seek vengeance on Hwadam, who murdered his mentor. The third is to capture and imprison the antagonist Hwadam, the leader of the goblins, and retrieve the stolen half of the flute with the help from the three wizards and Choraengi, his assistants. The film states in its prologue that if the goblins use the magic flute then the world will be plunged into chaos and disarray.

The film opens with the Pyohundaedeok blowing the magic flute in prison in the heavens for 3000 days in order to suppress the evil nature of the goblins. However, the three Taoist wizards (played by Young-chang Song, Jin-mo Joo, and Sang-ho Kim) accidentally open the prison doors, causing the goblins to regain their evil nature, steal the flute from the Pyohundaedeok, and come down to earth and enter people's bodies. Pyohundaedeok also falls to earth.

[Stage 1] Ordinary World - Joseon Dynasty era, the heavens; Jeonwuchi (played by Gang Dong-won) tricks the king and steals the bronze mirror, a treasure of the royal family, in order to help the people suffering from the famine. He then escapes on a donkey that he draws. In order to become the best wizard, he needs both the bronze mirror and bronze sword. He travels back and forth between the heavens and the real world through the picture frame with Choraengi (played by Yoo Hae-jin). While searching for the bronze sword, he meets and falls in love with a woman (played by Im Soo-jeong). He coincidentally fights goblins who have escaped from the prisons of the heavens, retrieves the magic flute from them, and returns to the heavens with the woman. He continues to reject the tutelage of his mentor (played by Baek Yoon-sik) Master Cheon-gwan and acts recklessly.

[Stage 2] The Call to Adventure - Joseon Dynasty era, the heavens; Jeonwuchi vows to protect the woman forever(Task 1). His mentor is murdered by Hwadam who attempts to steal the magic flute. Jeonwchi reads the message left by his mentor, 'Shoot the Geomungo case (taken from the legend of the Sageumgap from the Memorabilia of the Three Kingdoms)' and vows to have his revenge on Hwadam (Task 2). 
[Stage 3] Refusal of the Call - the heavens; Jeonwchi and Choraengi are falsely accused of murdering Master Cheon-gwan and as a result are sealed within a painting for 500 years by the three wizards (This can be seen as a refusal of the call by another party). Jeonwuchi is sealed in the painting with the half of the flute (The film then moves to a modern city 500 years later). According to Campbell, this is a moment in which Jeonwuchi becomes one who needs salvation, and he is stuck in an environment that renders his life meaningless for a while.

[Stage 4] Meeting with the Mentor - Modern day; Master Cheon-gwan, Jeonwuchi's mentor, is a special being. He travels through the heavens, Joseon kingdom, and the modern day to aide Jeonwuchi by offering him wisdom and predictions for the future. The three wizards play the role of the herald and assistant. They revive Jeonwuchi and Choraengi from the painting in order to defeat the demons that have appeared in the real world in 2009. According to Campbell's theory, Jeonwuchi and his supernatural assistants (the three wizards and Choraengi) need to fulfil the task of sealing the goblins and retrieving the flute for the peace of the world (Task 3).

[Stage 5] Crossing the First Threshold - Modern day; Jeonwuchi uses magical charms to fight the goblins with Choraengi in the modern day city. Jeonwuchi is continuously reminded of his mentor's words that he can only achieve true enlightenment through emptying the mind, and he slowly reaches an understanding of the true way of the Tao. He then fights goblins with an iron arm without magical charms and also risks entering into water even though he does not know how to swim (the Belly of the Whale in Kampbell's theory) and defeats a goblin. He finds the bronze sword in the relic storage room and uses his spells to remove the shackles on his ankle placed by the three wizards.

[Stage 6] Test, Allies, Enemies - Modern day; Jeonwuchi is reunited with the woman that he vowed to protect 500 years ago in the modern day and is faced with a new set of challenges. According to his mentor's prophecies, the woman is an antagonist that will guide Jeonwuchi to the place of his death; however, Jeonwuchi does his best to keep his promise by protecting her and fulfilling his first task. Choraengi and his assistants, the wizards become his opponents, and start serving Hwadam, the leader of the goblins. This presents new challenges for Jeonwuchi.

[Stage 7] Approach to the Innermost Cave - Modern day; With both Choraengi, who is controlled by Hwadam (steals Jeonwuchi's magical charms and gives them to Hwadam) and the woman who have become his antagonists, it can be said that Jeonwuchi has approached his innermost cave. However, Jeonwuchi sets out to save the woman. 
[Stage 8] The Ordeal - Modern day; Jeonwuchi duels with Hwadam without any magical charms. Jeonwuchi uses his final magical charm to save the woman rather than himself, says, "Is this the place of my death?", kisses the woman (The meeting with the goddess and apotheosis), and falls into the water.

[Stage 9] Reward - Modern day; It appears that Jeonwuchi sacrificed himself, but much like Campbell's strong hero, he does not die and comes back to life. Jeonwuchi fights Hwadam by drawing magical charms in the air with his fingers. He is exactly like Campbell's hero in the mono-myth as he fights with the bronze sword whilst flying around and using his spells with perfect ease. The three wizards and Choraengi become Jeonwuchi's assistants once again.

[Stage 10] The Road Back - The heavens, modern day; Hwadam fights with Jeonwuchi, Choraengi and the three wizards takes back the flute and blows it. The woman (revealed to be the alter ego of the Pyohundaedeok) hears the flute, comes to her senses, and stabs Hwadam with an apricot tree branch. This is as foretold by an old woman in Joseon dynasty. Jeonwuchi shoots an arrow at the Geomungo case at his mentor's house and pierces Hwadam who was hiding inside the case. The two battle each other as they weave in and out of the heavens and the real world. This is the part that corresponds to Campbell's stages of the magic flight and help from without. Jeonwuchi was able to defeat Hwadam with the help from both his mentor and the woman. In other words, they are the master of two worlds. This is similar to the hero recovering his ego through the grace of the assistant.

[Stage 11] Resurrection - Modern day; By destroying the flute that is said to have absolute power, Jeonwuchi destroys the source of good and evil itself. In short, he turns away from greed and regains his ego. This part falls a bit short as Vogler's stage of experiencing a change in the form of a climax and being born again before returning to the everyday life. Jeonwuchi can still use magic in the real world without the flute, but the woman (the Pyohundaedeok), the three wizards, and Choraengi are unable to ascend to the heavens and have remain in this world as well.

[Stage 12] Return with the Elixir - Modern day, utopia; Jeonwuchi, Choraengi, and the wizards remain near the woman who has now become an actress, and protect her. Jeonwuchi, the woman, and Choraengyi teleport to the same beach where Jeonwuochi showed to the woman 500 years ago. The film concludes with the life of freedom for a personal romance.

The analysis of the film <Jeonwuchi> yields results that are clearly different from the cyclical structure of Campbell and Vogler's theories. The film's rendition of Jeonwuchi is also arguably a bit to weak to be considered a Hollywood hero character. As shown in [Fig. 1], the film also shows a big difference in its stages 3,11 , and 12 . In contrast to the Jeonwuchi of the original 
text, the film's version focuses more on his personal growth, playful nature and the superficial beauty of the visuals.

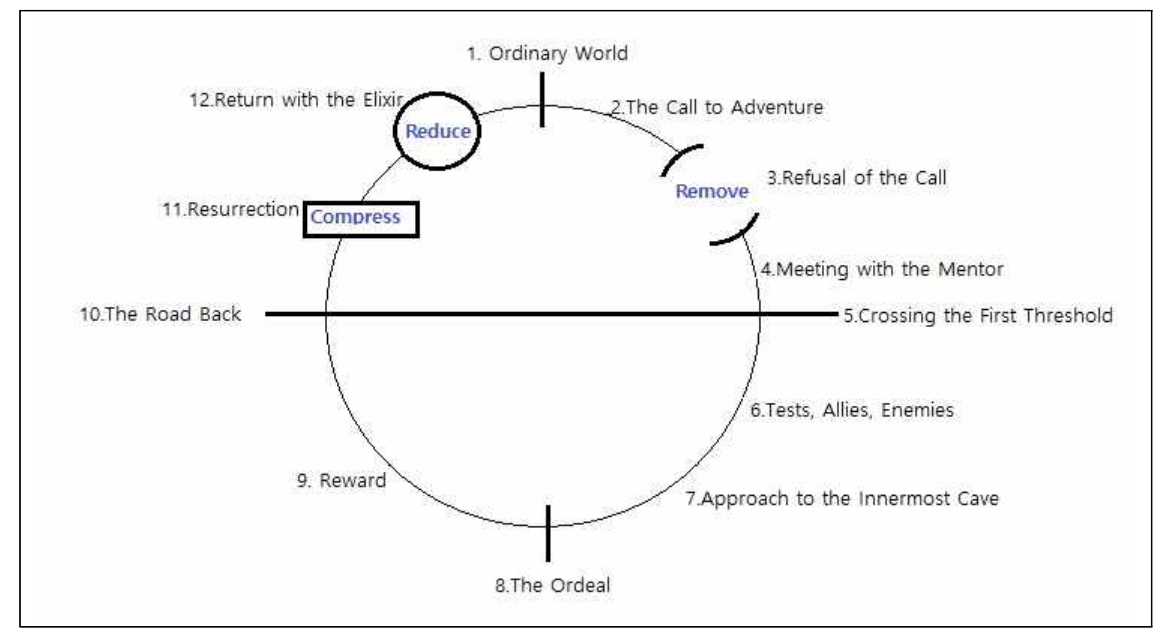

[Fig. 1] Hero's Journey of Movie <Jeonwuchi>

Seen from the perspective of Campbell's mono-myth, the discourse structure of the film became an inextricable obstacle for the stage heading towards the manifestation of heroism, the climax, and the life of freedom at the finale. The absence or shortage of additional meaning and events to expand the significance of the romance with the young widow (the actress Seo Ingyeong in the modern day and the alter ego of the Pyohundaedeok of the heavens) or the magical flute limited the scope of the film to an extremely personal heroic tale instead of one about a greater cause.

Much like the apotheosis at the climax of the narrative, the hero needs to undergo a final change and overcome the pains and confusion of a rebirth of the ego, finally earning a heroism that should be an example for eternity. This is why the creator needs to avoid a plot that rewards the hero (earn the elixir) even though he has not fulfilled his role. Vogler stated that the elixir is something that transcends all metaphorical meaning and brings both the hero and the audience closer to a great illumination.

As shown in [Fig. 1], the big difference between the film and Vogler's 12 stages is that the third stage 'Refusal of the Call' is depicted as being initiated not by the hero himself but by a different party (the three wizards) in the form of being sealed within a painting for 500 years. The reason to this is because, firstly, there is no need for refusing the call because the film already reveals that it is Hwadam is the one who murdered the mentor. Secondly, it can be 
seen as a plot device that brings the time and space of a movie to the present age of 2009 after 500 years.

Moreover, the eleventh stage of 'Resurrection' is the scene where Jeonwuchi destroys the flute that is said to have absolute power to control the harmony of the world with the bronze sword. This should be the great sequence in which the hero crosses the extremely challenging return threshold, and yet the film replaced this with a single scene that compresses the entire sequence into one aesthetically pleasing moment. The twelfth stage 'Return with the Elixir' is concluded in a way that Jeonwuchi decides to pursue his dubious romance with the woman by remaining in the real world and tele-porting to the beach after the flute is destroyed.

In spite of all this, the film <Jeonwuchi> can fit adequately well within the frame of the 'Hero's Journey.' The director sets the early part of the film in a chaotic time where the line between good and evil gets blurred and mixed, and he assigned Jeonwuchi with three tasks that can almost be seen to be trivial for amusement purposes. Jeonwuchi has become a victor who travels through the processes of personal growth and enlightenment as he struggles through the many challenges he faces in order to fulfil his tasks and learns from his mentor's teachings to 'empty the mind.' In other words, he has became a hero character of the everyday petit bourgeois.

\section{Conclusion and Implications}

This research was able to extract and arrange the characteristics of the heroic narrative in the classic novel <The Tales of Jeonwuchi: Jeonwuchi-jeon>, as seen in [Table 1]. The research also revealed that the tale had similarities with the components that made up Campbell's 'Hero's Journey'. The Nasonbon version in particular had an extremely similar plot to that of Campbell's hero narrative structure. The Ilsabon version, on the other hand, was different from the other versions in that it had elements such as the banishment from heaven motif, teacher and pupil, hardships such as arrests and death threats, government positions, realizing social justice, and saving the people.

This maximized the popular hero narrative and fantasy elements within the version and included more entertaining elements for its readers. Compared to other characters from classic novels who have rather simple personalities, Jeonwuchi shows various sides to his character by performing different kinds of Taoist magic. This proves that it is difficult to define his character to with a single keyword.

However, this research also found through the review and analysis of the hero character and 
discourse structure within the modern film <Jeonwuchi> that the ubiquity of the cultural industry becomes a rather significant problem in the process of transforming and recreating the subject of Korean mythology. In addition, the hero character in the film <Jeonwuchi : As the Taoist Wizard> is missing the symbolism and significance of Korean mythology. This could mean that unlike how Hollywood's Marvel and DC Comics created movies featuring hero stories about heroes who dedicate their lives for the community, the ubiquity that only stresses a general and appropriate discourse on heroism could possibly become the final milestone for the glocal cultural industry.

The film adopted the scene from Shakespeare's tragedy <Macbeth> in which the three witches prophesy, "Foul is fair, and fair is foul," and its protagonist Jeonwuchi acts mischievously and sometimes cheerfully like Don Quixote or SunWukong. This indicates that the film failed to capture the unique identity of the heroism that exists within the original text $<$ The Tale of Jeonwuchi> and the essential properties of the mono-myth.

If the film had adopted more of the elements that make up a 'hero story' in the different versions of <The Tale of Jeonwuchi> into its discourse structure, the film's direction and heroism could have had an authenticity that was closer to that of the original text. In the process of modification (transformation), the film had been made mostly different from the story of the archetypal Jeonwuch. That is why the director's attempt to create a 'Korean hero movie' led to the creation of a rather unnatural identity of a hero character.

Even though the film <Jeonwuchi> had removed, compressed and reduced three stages of Campbell's hero narrative theory in the application to its overall discourse structure, most of the other stages could be appropriately applied. This is why Joseph Campbell's 'Hero's Journey' theory is valuable for completing or analyzing a new story. Using this theory as a method for developing cultural content would appear to be more appropriate for today's global cultural content industry than using other composition theories.

The analysis that focused on the hero narrative within the <Jeonwuchi-jeon> and the film $<$ Jeonwuchi> that this paper attempted to carry out will be useful to develop cultural content with Korean classical novels. This paper agreed that there needs to be more attempts to synthesize and reorganize the values of the heroic elements from Jeonwuchi's literature narratives, legends, and classic novels with Campbells mythical imaginations. Jeonwuchi is a suitable popular hero character for providing enjoyment and entertainment, and also has value and potential for being made into global contents and for one source multi use purposes. Just as how the film <Jeonwuchi> attempted to jumpstart a 'Korean hero movie,' new hero characters can also be recreated and find popular appeal across the world. This is because hero 
characters in cultural content such as movies that use myths of the world and historical material can develop and change continuously and become like the heroes in Campbell's mono-myth.

\section{References}

[1] Christopher Vogler, The Writers Journey: Mythic Structure for Writers, (3rd Edition), USA: Michael Wiese Productions, (2007)

[2] In-Hwan Koo, (translation), Jeonwuchijeon, Korea: Sinwonmunhwasa, (2003)

[3] Il-lyul Kim, (translation), Jeonwuchijeon, Korea Classic Literature 25th, Korean Cultural Studies in Korea Univ., (1993)

[4] Sun-Keung Kwon, Classic Novels and Storytelling, Korea: Pagijong Press, Inc., (2018) http://www.yes24.com/Product/Goods/60643022

[5] Gwang-Soon Kim, History of Classic Novels, Korea: Saemunsa, (2006), pp.261-263.

https://www.aladin.co.kr/shop/wproduct.aspx?ItemId=1826365

[6] Hye-Eun Seo, The Study on Popularize Aspects and Its Meanings in the Novel-history in $<$ Jeon-Woo-Chi-Jeon>, EOMUNHAK-The Korean Language and Literature, (2012), No.115, pp.195-224.

[7] Chang-Soo Ahn, The Alteration of Heroic Romance on $<$ Jeon Woo Chi Jeon $>$, Theses on Korea Literature, (2011), No.59, pp.73-116.

[8] Joseph Campbell, The Hero with a Thousand Faces, (3rd Edition), USA: New World Library, (2008)

[9] Hwan-Kuk Jung, The Refraction and the Reverberation in the Tradition of "Jeonwochi", Journal of Korean Literary History, (2009), No.41, pp.213-239.

[10] Dong-Il Cho, Folk Hero Story, Mumye, (1992)

[11] Beom-Du Moon, <Jeonwoochijeon> Copy Research - Focusing on the Formation Process and Meaning, Hanminjok Emunhak, (1990), Vol.18, pp.1-29.

[12] Hyeon-Yang Kim, (translation), Jeonwoochijeon, Munhwagdongne, (2010)

[13] Je-Ho Jeong, The Tradition of Jeonwoochi and Its Transformation in Contemporary Media Narratives, The Research of the Korean Classic, (2018), Vol.43, pp.433-461.

[14] Sang-Gu Lee, Research on <Legend of Jeonwoochi> in Taein Island of Kwangyang, The Journal of Korean Language \& Literature Education, (2009), Vol.44, pp.353-394.

[15] Sang-Woo Joe, The Study on The Heroic Side and the Features of the Classic Novel Historical Significance, Journal of The Society of the Eastern Classic, (2018), Vol.71, pp.9-40. https://www.earticle.net/Article/A335021

[16] Il-Yong Park, The Ideology and Aesthetics of Heroic Novel, Journal of Korean Literature, (2002), Vol.7, 
pp.125-152.

[17] Sin-Eui Pak, The 4th Industrial Revolution and the Future of Art - How Art Has Responded to the Technological Change and Will Respond to?, Journal of Arts and Culture Management, (2017), Vol.10, No.1, pp.38-47.

[18] Jongho Lee, Comparative Study on Narrative Structures of Classic Novel $<$ Dyeonwuchijeon $>$ and Movie $<$ Jeonwuchi $>$, Journal of The Onji Studies, (2010), No.26, pp.243-270, UCI: G704-001782.2010..26.011

[19] Won-Seon Sin, A study on success ways about films contents of Korean classical novels -Focus on movie Woochi and the Servant-, National Cultural Debate, (2010), No.46, pp.365-402, UCI: G704-001644.2010..46.021

[20] Seung-Hoon Hyun, The Aesthetic Characteristics of Korean Superhero Film :Focus on Plot and Character of $<$ Jeonwoochi $>$, Journal of the Korea Contents Association, (2013), Vol.13, No.10, pp.132-139.

[21] Do-Hyun Cho, A Study on Modern Cinematic Adaptation and Circulation of $<$ Jeonwuchi $>$ Story - Focused on A film <Jeonwuchi $>$, Korean Language \& Literature, (2010), No.74, pp.371-390.

[22] Da-Jeong Jeong, A Study on Receptive Aspects of $<$ The Tale of Jeon Woo Chi>, the Original Novel of the Film <Jeon Woo Chi>, SookMyung University, Master Thesis, (2011)

[23] Sun-Kyung Jung, Modern Modification of Classic: Understanding of Space in the movie of Jeon-woo-chi, Journal of The Studies of Taoist and Culture, (2011), Vol.35, pp.143-169.

[24] Hae-Jin Cho, The Environmental Situation and Possibility on the Korea Fantasy Movie, Humanities Contents, (2011), No.21, pp.149-175.

[25] Yu-Kyung Seo, A Study on the Reading CheonUchi-Cheon in relation to Bruce Almighty with Culturally Expanded View, Journal of Reading Research, (2008), No.20, pp.201-231.

[26] Young-Hak Kim, Yong-Wook Lee, Movie Jeonwoochi, The Oriental Spirit and Korean-Fantasy, Journal of Korean Language Literature Association, (2012), No.53, pp.239-262.

[27] Su-Mee Chin, Jeon Woochi : The Taoist Wizard as a Film of Self-Reflexivity: Focusing on the Media Reproduction, Movie Media Center, Dongguk University, Scene Forum, (2017), No.26, pp.239-266.

[28] Yeo-Jeong Jo, Mythological Analysis of <Pan's Labyrinth> and <Woo-chi $>$ - with the 'Hero's Journey' Model as the Focus, Lingua Humanitatis, (2010), Vol.12, No.1, pp.113-139.

[29] https://www.yna.co.kr, "Jeonwuchi made it like this", Jan 17 (2010) 